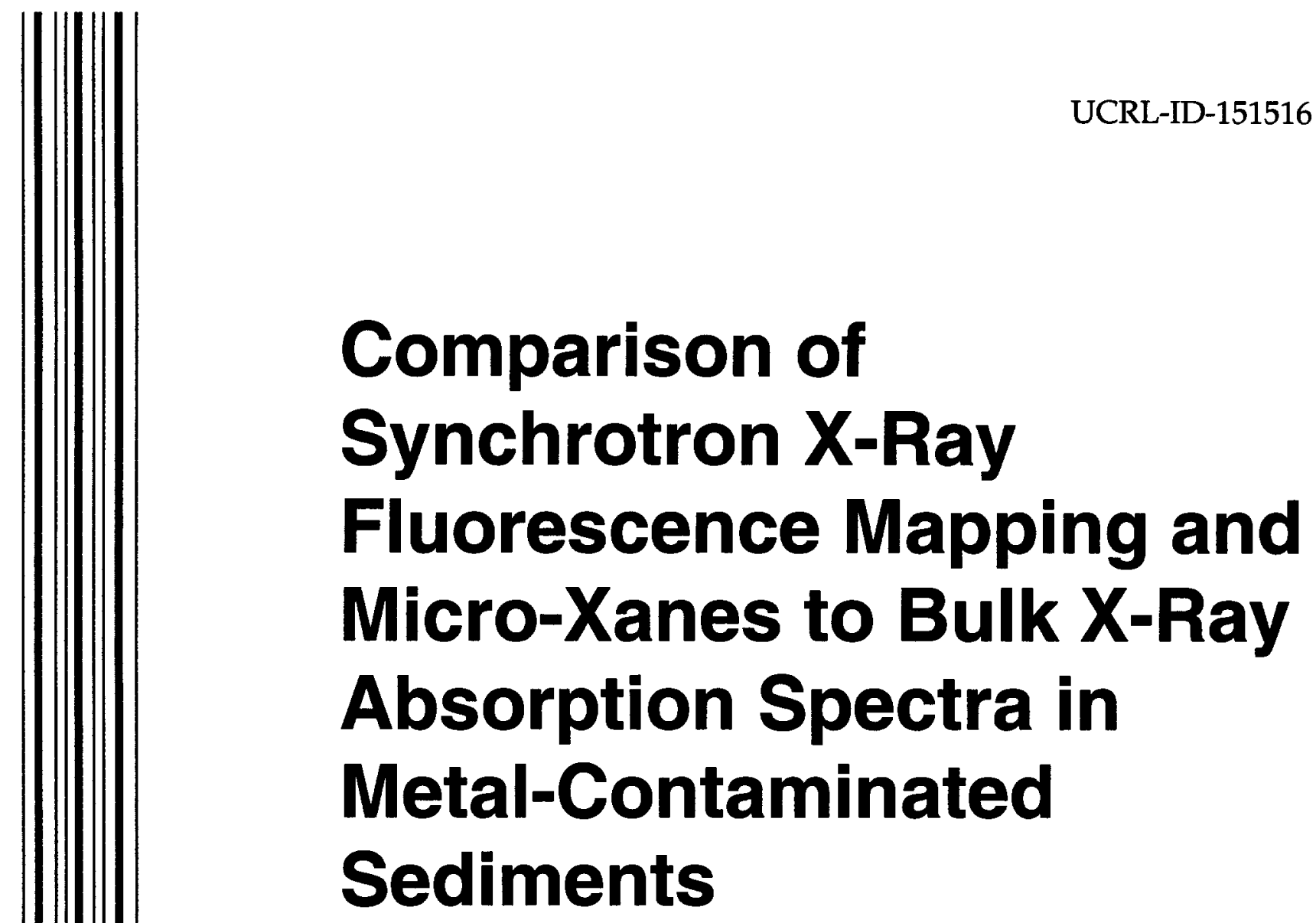

P. O'Day, S.A. Carroll, S. Bajt

U.S. Depertment of Energy

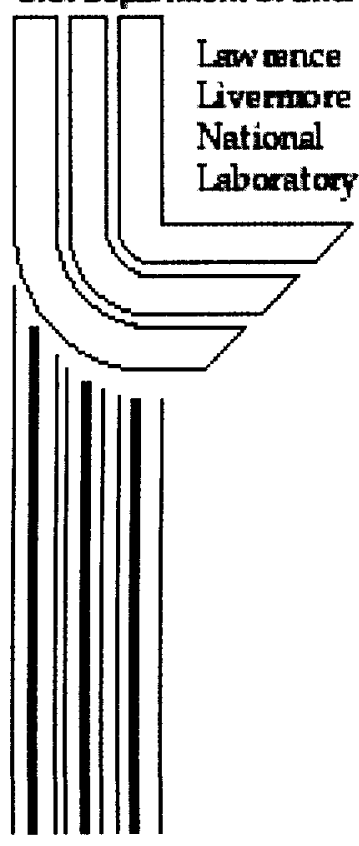

January 16, 2003 


\section{DISCLAIMER}

This document was prepared as an account of work sponsored by an agency of the United States Government. Neither the United States Government nor the University of California nor any of their employees, makes any warranty, express or implied, or assumes any legal liability or responsibility for the accuracy, completeness, or usefulness of any information, apparatus, product, or process disclosed, or represents that its use would not infringe privately owned rights. Reference herein to any specific commercial product, process, or service by trade name, trademark, manufacturer, or otherwise, does not necessarily constitute or imply its endorsement, recommendation, or favoring by the United States Government or the University of California. The views and opinions of authors expressed herein do not necessarily state or reflect those of the United States Government or the University of California, and shall not be used for advertising or product endorsement purposes.

This work was performed under the auspices of the U. S. Department of Energy by the University of California, Lawrence Livermore National Laboratory under Contract No. W-7405-Eng-48.

This report has been reproduced directly from the best available copy.

Available electronically at http://www.doc.gov/bridge

Available for a processing fee to U.S. Department of Energy

And its contractors in paper from

U.S. Department of Energy

Office of Scientific and Technical Information

P.O. Box 62

Oak Ridge, TN 37831-0062

Telephone: (865) 576-8401

Facsimile: (865) 576-5728

E-mail: reports@adonis.osti.gov

Available for the sale to the public from

U.S. Department of Commerce

National Technical Information Service

5285 Port Royal Road

Springfield, VA 22161

Telephone: (800) 553-6847

Facsimile: (703) 605-6900

E-mail: orders@ntis.fedworld.gov

Online ordering: http://www.ntis.gov/ordering.htm

OR

Lawrence Livermore National Laboratory

Technical Information Department's Digital Library

http://www.llnl.gov/tid/Library.html 
odayl.doc

oday.figl.doc

P. A. O'Day: oday@asu.edu

S. A. Carroll: carroll6@llnl.gov

S. Bajt: bajt@llnl.gov

GSE-CARS

Sector 13

Environmental/Geological Science

\title{
Comparison of Synchrotron X-ray Fluorescence Mapping and Micro-XANES to Bulk X-ray Absorption Spectra in Metal-Contaminated Sediments
}

\author{
Peggy A. O'Day ${ }^{1}$, Susan A. Carroll ${ }^{2}$, and Sasa Bajt ${ }^{2}$ \\ ${ }^{1}$ Arizona State University, Tempe, AZ 85287-1404 USA \\ ${ }^{2}$ Lawrence Livermore National Laboratory, Livermore CA 94551 USA
}

\section{Introduction}

Synchrotron X-ray absorption spectroscopy (XAS) is one of the few techniques that can supply molecular-scale information for a variety of elements at concentrations relevant to natural systems in non-vacuum conditions. Bulk XAS analysis supplies the dominant chemical bonding mode(s) for a specific element. In complex materials such as natural soils and sediments, however, the dominant mode may not necessarily be the most reactive because changes in speciation at surfaces may results in changes in reactivity. Our previous work at Naval Air Station (NAS) Alameda (CA) focused on in situ metal chemistry in surface and deep sediments, and the impact of metal mobility by sediment oxidation. Estuary sediments at the Alameda Naval Station Air in California have elevated metal concentrations that increase with increasing depth. The metal concentrations in these sediments are: $\mathrm{Cd}(10-350 \mathrm{ppm}), \mathrm{Cr}(200-1000 \mathrm{ppm}), \mathrm{Cu}(100-$ $230 \mathrm{ppm}), \mathrm{Pb}(200-1200 \mathrm{ppm})$ and $\mathrm{Zn}(250-600 \mathrm{ppm})$. We have extensively characterized these sediments using bulk XAS and other non-synchrotron supporting methods [1].

In this experiment, we collected fluorescence element maps using synchrotron X-ray microprobe of unreacted and seawater oxidized sediment samples from Alameda NAS to determine the spatial distribution and correlation of lead, zinc, and iron. We then compared micro-XANES spectra for lead and zinc collected with the X-ray microprobe to previously collected bulk XANES spectra. The results from our bulk XAS characterization of the sediments showed both oxide and sulfide components for the trace metals. However, the bulk XAS data were not able to identify the composition of the oxide component (i.e. carbonate or hydroxide), nor could absorbed species or solid solutions be definitively identified. Our objective in using micro-XANES and fluorescence element maps was to attempt a more precise identification of metal speciation in or on individual particles.

\section{Methods and Materials}

Data was collected in February 2001, on GeoSoilEnviroCARS (GSECARS) Sector 13 undulator beamline (13-ID-C) with a $\mathrm{Si}(111)$ monochromator and K-B focusing mirrors. Fluorescence element maps and micro-XANES were collected with a $\sim 5 \mu \mathrm{m}$ beam spot size. For micro-XANES, 3-4 scans were average $d$ for each spot. Sample particles were dispersed with alcohol onto glass slides. Samples mounted in epoxy we also tested but particles were not dispersed adequately for mapping. Previous data collection and analyses of bulk XAS data are described in [ 1 and 2].

\section{Results}

Element mapping of lead, zinc, and iron showed a close spatial association among these elements in the sediment particles, with generally positive correlations between zinc and iron, or between lead and iron. A significant problem with X-ray microprobe sample preparation is dispersion and separation of individual particles. We found that small particles tended to clump together, making it difficult to interpret spatial relationships among the mapped elements using the $\sim 5 \mu \mathrm{m}$ beam spot size. Figure 1 compares bulk XANES data collected at the Stanford Synchrotron Radiation Laboratory to micro-XANES collected with a $5 \mu \mathrm{m}$ beam spot. Good signal-to-noise was obtained for micro-XANES measurements. For zinc and lead spectra, bulk and micro-XANES are generally similar for the leached sample, although there are some differences among different spot measurements. Analyses of zinc and lead bulk EXAFS spectra showed that zinc was present in both sulfide and oxide phases, but that lead was present in only oxide phases [1]. Differences among the micro-XANES spectra shown in Fig. 1 reflect either heterogeneity among different particles, or overlap of particles with different metal speciation.

\section{Discussion}

Micro-XAS has the potential to advance our understanding of trace metal biogeochemistry in contaminated sediments by spatially examining the molecular bonding of trace metals in the sediments. However, the current size of the beam spot $(5 \mu \mathrm{m})$ may be too large to analyze individual grains for many natural environments, as was the case for our sediments that contain grains that are probably less than $2 \mu \mathrm{m}$ in general. Our results indicate that beam spots sizes between 0.5 and $1 \mu \mathrm{m}$ would provide the necessary spatial resolution for successful microprobe mapping and XANES data collection to unravel the complex geochemistry present in natural sediments. Although a smaller beam size might decrease fluorescence signal, we found high signal-to-noise for these samples, suggesting that smaller beam sizes are feasible. In the absence of a smaller beam spot size, success of microprobe mapping and XANES data collection could be achieved by dispersing fine particles on a substrate such that individual particles can be imaged and analyzed. However, the dispersal may involve the use solvents that may react with the sediments. Quantitative XANES analysis also requires a good reference compound library for accurate spectral pattern matching. 


\section{Acknowledgments}

This work is supported by the National Science Foundation (EAR-9629276 and EAR-0073984 to O'Day).

Use of the Advanced Photon Source was supported by the U.S. Department of Energy, Basic Energy Sciences, Office of Science, under Contract No. W-31-109-Eng-38. Thanks to M. Newville and S. Sutton, GSE-CARS-CAT.

\section{References}

[1] O'Day, P. A., Carroll, S. A., Randall, S., Martinelli, R. E., Anderson, S. L., Knezovich, J. P., and Jelinski, J. (2000), Environ. Sci. Tech. 34, 3665-3673.

[2] Carroll, S. A.; Randall, S.; O'Day, P. A.; Bono, A.; Esser, B.; Luther, G. W., III, Lawrence Livermore National Laboratory: 1999; LLNL-UCRL-ID-135193; http://www.llnl.gov/tid/lof/.
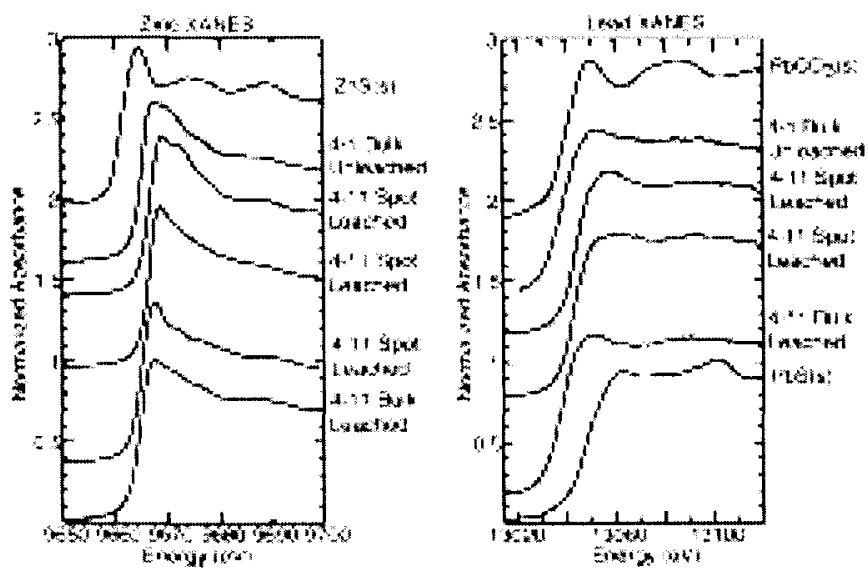

Fig. 1. Comparison of bulk and micro-XANES (spot) spectra for zinc and lead from NAS Alameda estuary sediments. Leached samples were reacted with seawater in the laboratory for 3 months to simulate oxidation. Reference sulfide and carbonate compound spectra are shown for comparison. 